\title{
Self-assembled manganese dioxide nanowires as electrode materials for electrochemical capacitors
}

\author{
Suk Fun Chin ${ }^{\mathrm{a}, *}$, Suh Cem Pang a, Marc A. Anderson ${ }^{\mathrm{b}}$ \\ a Department of Chemistry, Faculty of Resource Science and Technology, Universiti of Malaysia Sarawak, 94300, Kota Samarahan, Sarawak, Malaysia \\ ${ }^{\mathrm{b}}$ Environmental Chemistry and Technology, University of Wisconsin-Madison, WI, 53706-1481, USA
}

\section{A R T I C L E I N F O}

Article history:

Received 2 July 2010

Accepted 7 September 2010

Available online $\mathrm{xxxx}$

Keywords:

Manganese dioxide

Dialysis

Self-assembly

Electrochemical capacitors

\begin{abstract}
A B S T R A C T
The microstructure and morphology of sol-gel derived manganese dioxide $\left(\mathrm{MnO}_{2}\right)$ xerogels were affected by the synthesis conditions and post synthesis heat treatment. Manganese dioxide nanoparticles in sol that were dialyzed to more acidic $\mathrm{pH}$ ( $\mathrm{pH}$ 5.7) value were observed to self-assemble into nanowires, whereas nondialyzed sols remained nanoparticulate in nature. $\mathrm{MnO}_{2}$ xerogels of disordered nanowire network exhibited comparatively higher porosity and BET surface areas. The electrochemical properties of both $\mathrm{MnO}_{2}$ nanowire and nanoparticle thin-film electrodes were evaluated using cyclic voltammetry in a mild aqueous electrolyte $\left(0.1 \mathrm{M} \mathrm{Na}_{2} \mathrm{SO}_{4}\right)$. The charge capacities of $\mathrm{MnO}_{2}$ nanowire-based thin-film electrodes were substantially higher $(\sim 800 \mathrm{~F} / \mathrm{g})$ than those of nanoparticulate thin-film electrodes $(\sim 700 \mathrm{~F} / \mathrm{g})$.
\end{abstract}

(C) 2010 Published by Elsevier B.V.

\section{Introduction}

Over the past decade, there has been a growing interest in the development of electrochemical capacitors (ECs) or supercapacitors as high power density charge storage devices due to the exponential growth of portable electronics and communication devices product such as laptops, cellular phones, MP3 players and personal digital assistants (PDA). Electrochemical capacitors are hybrid between batteries and conventional capacitors with higher energy density than conventional capacitors, and with longer cycle life as well as higher power density than batteries [1]. Many transition metal oxides have been shown to be excellent electrode materials for the fabrication of electrochemical capacitors. Hydrous ruthenium oxide $\left(\mathrm{RuO}_{2} \cdot \mathrm{xH}_{2} \mathrm{O}\right)$ was shown to exhibit very high specific capacitance and good cycling reversibility $[2,3]$. A specific capacitance value as high as $720 \mathrm{~F} / \mathrm{g}$ was reported for ruthenium oxide-carbon composite electrodes in strong acidic electrolytes [4]. However, these materials are very expensive, toxic in nature and require the use of strong acidic electrolytes ( $5 \mathrm{M} \mathrm{H}_{2} \mathrm{SO}_{4}$ ) which have limited their commercial applications. Thus, various metal oxides such as $\mathrm{NiO}_{x}, \mathrm{CoO}_{x}, \mathrm{SnO}_{2}$ and $\mathrm{MnO}_{x}$ have been extensively investigated as alternative electrode materials for electrochemical capacitors [5-8]. Recently, several studies have shown that $\mathrm{MnO}_{2}$ thin films are very promising electrode materials for the fabrication of electrochemical capacitors. These thin films have been shown to be chemically stable, high in specific

\footnotetext{
* Corresponding author. Tel.: +60 82 582999; fax: +60 82583160 . E-mail address: sfchin@frst.unimas.my (S.F. Chin).
}

capacitance and highly reversible $[9,10]$. A specific capacitance value as high as $700 \mathrm{~F} / \mathrm{g}$ was achieved for $\mathrm{MnO}_{2}$ thin films in mild aqueous electrolyte [11,12]. Furthermore, $\mathrm{MnO}_{2}$ is low cost, non-toxic and environmentally friendly in nature.

The electrochemical property of the electrode materials is affected by their microstructure and morphology [13]. One-dimensional nanostructured materials such as nanotubes, nanowires and nanorods have demonstrated to be more favorable morphology for electrode materials as they provide short diffusion path-lengths to ions and excitons, leading to high charge/discharge rates [14]. Furthermore, one-dimensional nanostructure can reduce diffusion resistance of electrolytes in rapid charge/discharge processes. Nanowires of $\mathrm{SnO}_{2}$ and $\mathrm{V}_{2} \mathrm{O}_{5}$ were shown to have significantly improved the rate capability of thin-film electrodes for electrochemical capacitors as compared to nanoparticulate thin-film electrodes [15-17].

Conventionally, $\mathrm{MnO}_{2}$ nanowires were prepared by hydrothermal treatment of $\mathrm{MnO}_{2}$ nanoparticles in water or ammonia solution at high temperature $\left(120-160^{\circ} \mathrm{C}\right)[18,19]$. Recently, some researchers had used Pluronic P123 as structure directing agent to synthesize $\mathrm{MnO}_{2}$ nanowires at room temperature [20]. However, this copolymer is very expensive and it is tedious to remove the copolymer from the end product after synthesis. In the present work, we have successfully prepared $\mathrm{MnO}_{2}$ nanowires via the self-assembly of $\mathrm{MnO}_{2}$ nanoparticles using the dialysis method. This synthesis approach is simple, without the need to use any structure directing surfactant or template, and can be carried out at ambient temperature. As such, this synthesis approach can potentially be used for commercial production of nanowire-based $\mathrm{MnO}_{2}$ electrode materials suitable for the fabrication of thin-film electrochemical capacitors and other related charge storage devices. To the best of our knowledge, this is 